\title{
ABNORMALITIES OF PROXIMAL FEMORAL GROWTH AFTER SEVERE PERTHES' DISEASE
}

\author{
PAUL D. SPONSELLER, SHEKHAR S. DESAI, MICHAEL B. MILLIS
}

From the Children's Hospital of Boston

\begin{abstract}
We studied the pattern of proximal femoral growth after severe Perthes' disease (Catterall grade III or IV) by retrospective analysis of serial radiographs in 52 hips (46 patients). Our aim was to determine the relationship between proximal femoral growth abnormalities and metaphyseal cysts, epiphyseal extrusion, physeal narrowing, and extensive epiphyseal necrosis. The average follow-up after treatment was 9.8 years (range 4 to 16 years), and 37 of the hips were followed to skeletal maturity.

Slowing of proximal femoral growth was common: symmetrical abnormality was seen in $\mathbf{2 6}$ hips and asymmetrical abnormality in nine. However, definite premature closure of the proximal femoral physis was seen in only three hips. Abnormality seemed to be due to altered growth velocity rather than to bar formation in most cases. Metaphyseal cysts, epiphyseal extrusion and physeal narrowing during the active stage of the disease, alone or in combination, were found to be neither sensitive nor specific predictors of the subsequent growth pattern.
\end{abstract}

Perthes' disease is recognised as primarily involving the proximal femoral epiphysis. Most reports have therefore addressed changes in this region, since the long-term outcome has been shown to be related to its sphericity and congruency (Stulberg, Cooperman and Wallensten 1981). However, changes also occur in the physis and the metaphysis but these have rarely been discussed (Barnes 1980; Bowen, Foster and Hartzell 1984).

Bowen et al (1984) proposed two types of physeal growth abnormality secondary to Perthes' disease: symmetrical (central) and asymmetrical (lateral), and stated that both of these involve early closure of the growth plate. They observed one of these two patterns in $21 \%$ of hips in their study, and felt that the occurrence and the type of growth plate abnormality correlated with and could be predicted by the following factors: extensive metaphyseal 'cyst' formation, narrowing of the physis in

P. D. Sponseller, MD, Assistant Professor

The Johns Hopkins Medical Institution, 600 North Wolfe Street, Baltimore, Maryland 21205, USA.

S. S. Desai, MD, Orthopaedic Resident

Maimonides Medical Center, 4802 Tenth Avenue, Brooklyn, New York 11219, USA

M. B. Millis, MD, Attending Orthopaedic Surgeon

The Children's Hospital of Boston, 300 Longwood Drive, Boston, Massachusetts 02115, USA

Correspondence should be sent to Dr P. D. Sponseller.

(C) 1989 British Editorial Society of Bone and Joint Surgery $0301-620 X / 89 / 4136 \$ 2.00$

J Bone Joint Surg [Br] 1989;71-B:610-4. the disease, marked extrusion of the femoral epiphysis, and greater than $50 \%$ necrosis of the epiphysis.

We have studied the correlation of the first three factors with physeal growth disturbance in a group of patients, all of whom had greater than $50 \%$ epiphyseal necrosis (Catterall (1971) grade III or grade IV), with a view to more accurate prognosis and planning for surgery.

\section{PATIENTS AND METHODS}

We retrospectively analysed the notes and radiographs of all patients undergoing femoral or innominate osteotomies for Perthes' disease involving more than one half of the epiphysis seen at the Children's Hospital, Boston, between 1967 and 1982. Ninety-five patients met these criteria; $88(93 \%)$ were located and evaluated for current follow-up. The 40 patients who were treated by femoral osteotomy were excluded from the study because the effects of this procedure could not have been differentiated from physeal growth abnormalities secondary to the disease process itself. Forty-six patients with 46 involved hips had been treated by innominate osteotomy; six of them had Perthes' disease of the contralateral hip treated by orthotic containment. These 52 hips formed the series for the present study (Table I).

Serial radiographs throughout the stage of epiphyseal involvement were available for all the patients and these were analysed by two of the authors for the risk factors listed above: growth plate narrowing, epiphyseal extrusion and metaphyseal 'cysts'. Cysts were defined as 
Table I. Radiographic analysis of 52 hips with Perthes' disease

\begin{tabular}{|c|c|c|c|c|c|c|c|c|c|c|c|c|}
\hline \multirow{3}{*}{$\frac{\text { Patient }}{1}$} & \multirow{3}{*}{$\begin{array}{l}\text { Catterall } \\
\text { grade }\end{array}$} & \multirow{2}{*}{\multicolumn{2}{|c|}{$\begin{array}{l}\text { Size (\%) and } \\
\text { location of cyst }\end{array}$}} & \multirow{3}{*}{$\begin{array}{c}\begin{array}{l}\text { Epiphyseal } \\
\text { extrusion } \\
\text { (per cent) }\end{array} \\
0\end{array}$} & \multirow{3}{*}{$\begin{array}{l}\begin{array}{l}\text { Physeal closure } \\
\text { (years)* }\end{array} \\
15=\end{array}$} & \multicolumn{5}{|c|}{ Difference in millimetres $\dagger$} & \multicolumn{2}{|c|}{ Growth disturbance $\ddagger$} \\
\hline & & & & & & \multirow{2}{*}{$\frac{\text { MTV + }}{0}$} & \multirow{2}{*}{$\frac{\text { MTH }}{10}$} & \multirow{2}{*}{$\frac{N W}{5}$} & \multirow{2}{*}{$\frac{\text { NL }}{5}$} & \multirow{2}{*}{$\frac{\overline{E H}}{7}$} & \multirow{2}{*}{$\begin{array}{l}\text { Predicted } \\
\mathrm{C}\end{array}$} & \multirow{2}{*}{$\begin{array}{l}\text { Observed } \\
C\end{array}$} \\
\hline & & $<25$ & Central & & & & & & & & & \\
\hline $2 \mathrm{R}$ & 4 & $<25$ & Central & 20 & $11.25=$ & \multirow{2}{*}{\multicolumn{2}{|c|}{ Not applicable }} & & & & $\mathrm{C}$ & $\mathrm{C}$ \\
\hline L & 4 & & & 20 & $11.25=$ & & & & & & $N$ & $\mathrm{C}$ \\
\hline 3 & 3 & 100 & Central & 0 & $14=$ & 10 & 5 & 3 & 5 & 5 & $\mathrm{C}$ & $\mathrm{L}$ \\
\hline 4 & 4 & 25 to 50 & Lateral & 15 & $16=$ & 3 & 5 & 5 & 0 & 2 & $\mathrm{~L}$ & $w$ \\
\hline 5 & 4 & $<25$ & Lateral & 12 & $13=$ & 5 & 10 & 2 & 10 & 7 & $\mathrm{~L}$ & L \\
\hline 6 & 3 & 100 & Central & 25 & $13.5=$ & 2 & 0 & 4 & 4 & 3 & $\mathrm{C}$ & $\mathrm{N}$ \\
\hline $7 R$ & 4 & 25 to 50 & Central & 0 & Open at 12 & \multirow{2}{*}{\multicolumn{2}{|c|}{ Not applicable }} & & & & $\mathrm{C}$ & C \\
\hline $\mathrm{L}$ & 4 & $>75$ & Central & 0 & Open at 12 & & & & & & $\mathrm{C}$ & $\mathbf{L}$ \\
\hline 8 & 4 & $<25$ & Central & 20 & $15.5=$ & 5 & 6 & 0 & 5 & 3 & $\mathrm{C}$ & C \\
\hline 9 & 4 & 100 & Central & 10 & Open at 14 & 3 & 20 & 8 & 15 & 6 & $\mathrm{C}$ & C \\
\hline 10 & 3 & & & 12 & $?=$ & 5 & 3 & 5 & 5 & 5 & $\mathrm{~N}$ & $N$ \\
\hline 11 & 3 & - & & 20 & $15=$ & 2 & 15 & 2 & 10 & 4 & $\mathbf{N}$ & L \\
\hline 12 & 4 & 100 & Central & 20 & $10 \neq$ & 25 & 0 & 5 & 20 & 10 & $\mathrm{C}$ & C \\
\hline 13 & 4 & 100 & Central & 14 & $20=$ & 0 & 10 & 5 & 5 & 2 & $\mathrm{C}$ & L \\
\hline 14 & 3 & $<25$ & Lateral & 10 & $15=$ & 5 & 25 & 5 & 5 & 5 & L & L \\
\hline 15 & 4 & 50 to 75 & Central & 30 & $15=$ & 5 & 5 & 5 & 5 & 10 & C & w \\
\hline 16 & 3 & - & & 10 & $?=$ & 10 & 20 & 5 & 15 & 5 & $\mathrm{~N}$ & C \\
\hline 17 & 3 & $<25$ & Lateral & 0 & Open at 14 & 3 & 10 & $\mathbf{0}$ & 5 & 5 & L & L \\
\hline 18 & 3 & - & & 0 & $16=$ & 0 & 10 & 0 & 15 & 10 & $\mathrm{~N}$ & $\mathbf{L}$ \\
\hline 19 & 3 & 100 & Central & 0 & $15=$ & 0 & 0 & 2 & 5 & 7 & C & $w$ \\
\hline 20 & 3 & & & 0 & $15=$ & 0 & 5 & 0 & 5 & 2 & $\mathrm{~N}$ & $\mathrm{~N}$ \\
\hline 21 & 4 & 25 to 50 & Central & 15 & $17=$ & 8 & 5 & 0 & 5 & 7 & $\mathrm{C}$ & $N$ \\
\hline 22 & 3 & - & & 10 & Open at 15 & 2 & 3 & 1 & 0 & 1 & $N$ & $\mathrm{~N}$ \\
\hline 23 & 3 & 100 & Central & 10 & Open at 12 & 11 & 0 & 6 & 15 & 7 & $\mathrm{C}$ & C \\
\hline 24 & 3 & 50 to 75 & Lateral & 22 & $16=$ & & & & & & & \\
\hline 25 & 4 & 100 & Central & 5 & $15 \neq$ & 10 & 20 & 5 & 15 & 5 & $\mathrm{C}$ & C \\
\hline $26 \mathrm{R}$ & 4 & 50 to 75 & Central & 20 & Open at 13 & & & & & & $\mathrm{C}$ & $N$ \\
\hline $\mathrm{L}$ & 4 & - & & 20 & Open at 13 & Not app & cable & & & & $\mathrm{N}$ & $N$ \\
\hline 27 & 3 & & & 5 & $16 \neq$ & 10 & 15 & 10 & 10 & 10 & $\mathrm{~N}$ & $\mathrm{C}$ \\
\hline 28 & 4 & 50 to 75 & Central & 20 & $14=$ & 10 & 5 & 0 & 0 & 5 & $\mathrm{C}$ & $N$ \\
\hline 29 & 4 & 100 & Central & 10 & Open at 13 & 10 & 0 & 8 & 5 & 3 & $\mathrm{C}$ & C \\
\hline 30 & 3 & 50 to 75 & Central & 5 & $16=$ & 3 & 0 & 0 & 10 & 5 & $\mathrm{C}$ & c \\
\hline 31 & 4 & 50 to 75 & Central & 40 & $14 \neq$ & 8 & 12 & 5 & 20 & 8 & $\mathrm{C}$ & C \\
\hline 32 & 4 & 50 to 75 & Central & 10 & $12 \neq$ & 15 & 17 & 0 & 20 & 10 & $\mathrm{C}$ & c \\
\hline 33 & 4 & 25 to 50 & Lateral & 15 & $14=$ & 0 & 20 & 10 & 15 & 10 & $\mathrm{~L}$ & L \\
\hline 34 & 3 & 25 to 50 & Medial & 0 & $15=$ & 10 & 15 & 0 & 15 & 10 & $\mathbf{M}$ & C \\
\hline 35 & 3 & 25 to 50 & Lateral & 0 & $15=$ & 2 & 0 & 5 & 5 & 3 & L & $N$ \\
\hline 36 & 3 & 25 to 50 & Medial & 0 & Open at 12 & 0 & 5 & 0 & 5 & 0 & $\mathrm{C}$ & $\mathbf{N}$ \\
\hline 37 & 3 & & & 10 & Open at 12 & 0 & 5 & 5 & 0 & 5 & $\mathbf{N}$ & $N$ \\
\hline 38 & 4 & 50 to 75 & Lateral & 15 & $16=$ & 0 & 15 & 0 & 5 & 3 & $\mathrm{~L}$ & L \\
\hline 39 & 3 & 50 to 75 & Lateral & 25 & $15=$ & 2 & 7 & 0 & 0 & 5 & $\mathrm{C}$ & $\mathrm{N}$ \\
\hline 40R & 3 & 50 to 75 & Central & 25 & $15=$ & & & & & & $\mathrm{C}$ & C \\
\hline $\mathrm{L}$ & 3 & 50 to 75 & Central & 25 & $15=$ & Not app & cable & & & & $\mathrm{C}$ & C \\
\hline 41 & 3 & 25 to 50 & Central & 10 & $?=$ & 5 & 10 & 5 & 5 & 10 & L & c \\
\hline $42 R$ & 3 & - & & 20 & Open at 13.5 & & & & & & $\mathrm{~N}$ & $N$ \\
\hline $\mathrm{L}$ & 3 & & & 20 & Open at 13.5 & Not app & cable & & & & $N$ & $N$ \\
\hline 43 & 4 & 25 to 50 & Lateral & 30 & $16=$ & 10 & 10 & 5 & 10 & 5 & L & C \\
\hline 44 & 4 & 100 & Central & 16 & Open at 14 & 0 & 0 & 5 & 0 & 5 & $\mathrm{C}$ & $N$ \\
\hline 45 & 3 & 25 to 50 & Medial & 10 & $14=$ & 20 & 15 & 5 & 30 & 8 & $\mathrm{C}$ & C \\
\hline $46 \mathrm{R}$ & 4 & 25 to 50 & Central & 0 & $12=$ & & & & & & $\mathrm{C}$ & C \\
\hline $\mathrm{L}$ & 4 & 75 to 100 & Central & 10 & Open at 12 & Not app & cable & & & & $\mathrm{C}$ & C \\
\hline
\end{tabular}

* = bilateral closure at same age, $\neq$ bilateral closure at different ages + See text and Figure 1 for description of parameters

$\ddagger C$, central; $L$, lateral; $M$, medial; $N$, none; $W$, widening only 
physeal-metaphyseal radiolucencies with well-defined or poorly-defined margins. Twenty-seven hips showed Catterall grade III changes and 25 grade IV. Subsequent sequential films were reviewed to determine the age and pattern of physeal growth. (Fig. 1):

On the final radiographs we measured the following

Neck width at the narrowest portion of the neck

Neck length from the centre of the line joining the base of the greater and the lesser trochanter to the physeal scar (in skeletally mature hips) or to the physeal plate (in nearly mature hips). This measurement was made along the best estimate of the central axis of the femoral neck. An idea of the symmetry of physeal growth in unilateral cases was obtained by measuring the relationship between the tip of the greater trochanter and the metaphysis in two dimensions. The horizontal distance between the tip of the greater trochanter and the most proximal portion of the metaphysis (MTH) was measured as an indication of transverse growth. The vertical distance between the tip of the greater trochanter and the most proximal portion of the metaphysis (MTV) was measured as an indication of vertical growth.
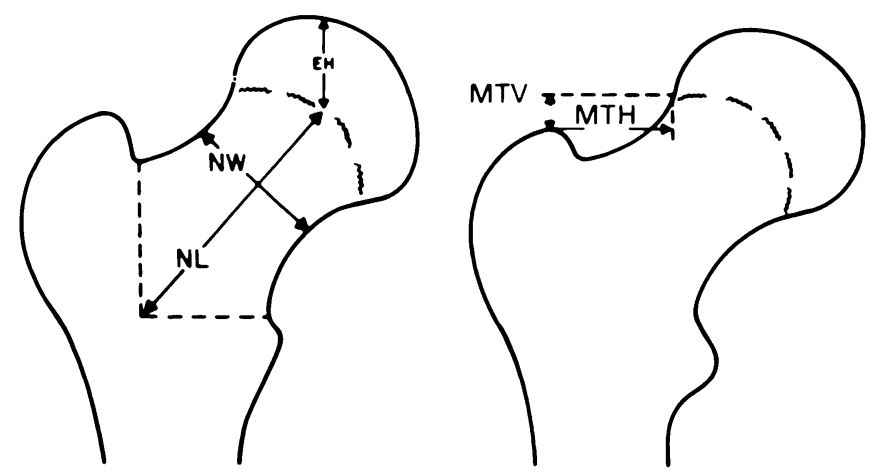

Fig. 1

Radiographic parameters, as defined in text: EH, epiphyseal height: NL, neck length; NW, neck width; MTH, horizontal metaphysealtrochanteric distance; MTV, vertical metaphyseal-trochanteric distance.

Neck-shaft angle

Epiphyseal height as the vertical distance between the highest point on the femoral head and the physeal scar below it.

Articulotrochanteric quotient, an estimate of the overall growth of both the metaphyseal and epiphyseal components, was obtained as described by Stulberg et al (1981).

In unilateral cases, the contralateral normal hip was also measured for comparison. Differences in any of the above-mentioned parameters of over $5 \mathrm{~mm}$ were considered to represent a growth disturbance. In cases with bilateral involvement, the growth disturbance was estimated on the basis of the overall visual appearance, neck-shaft angle and articulotrochanteric quotient.
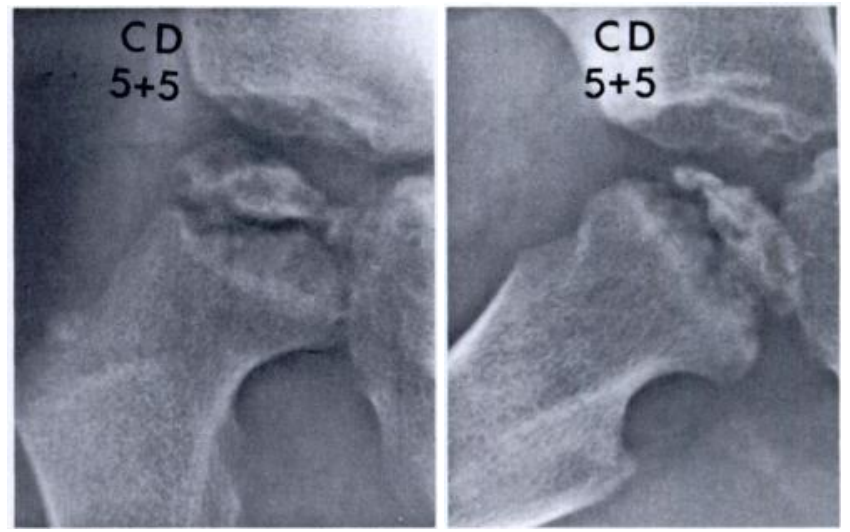

Fig. 2a

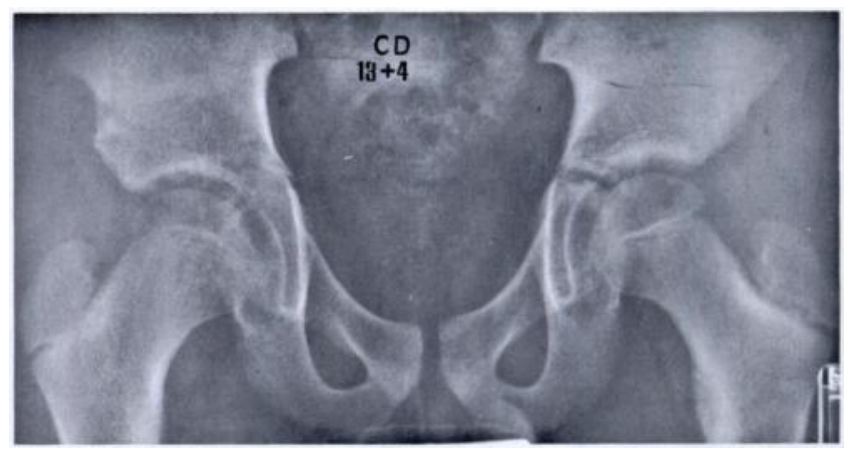

Fig. $2 b$

Extensive metaphyseal lucencies with complete epiphyseal involvement, but no significant growth abnormality. Figure 2a - At 5 years 5 months. Figure $2 b-$ Eight years later.

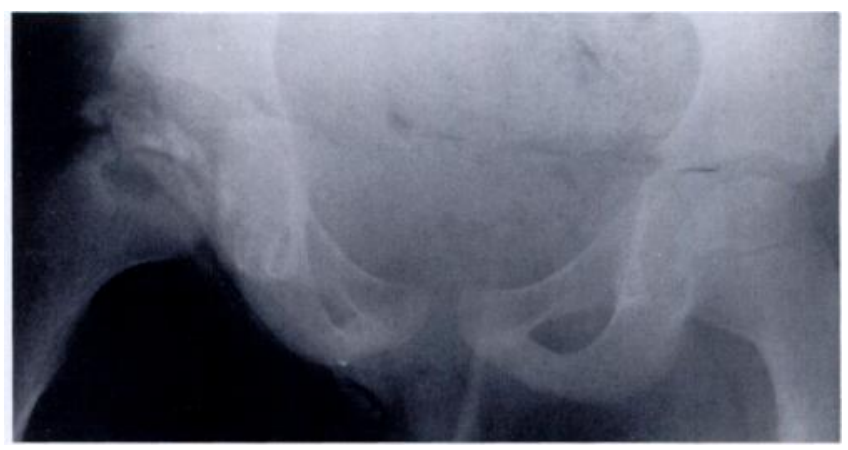

Fig. 3a

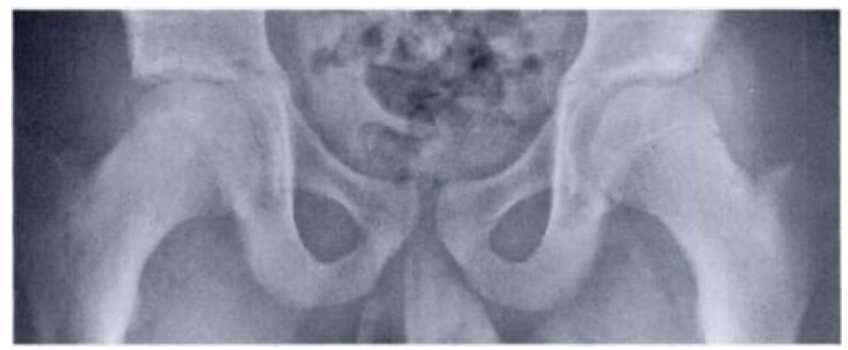

Fig. 3b

Figure $3 a$ - Focal central 'cyst' in an older child. Figure $3 b-$ Six years later there is no central abnormality of growth and only minimal neck widening and shortening. 


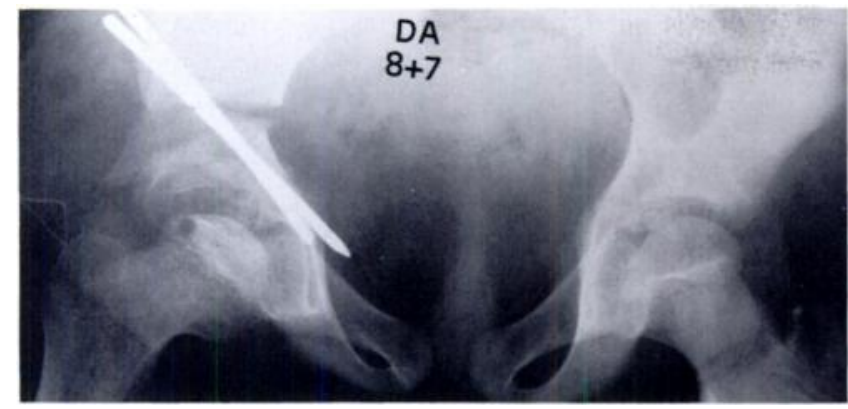

Fig. 4a

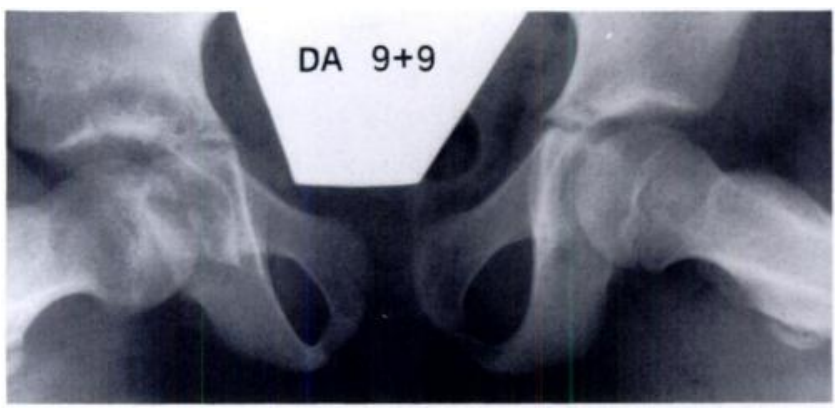

Fig. 4b

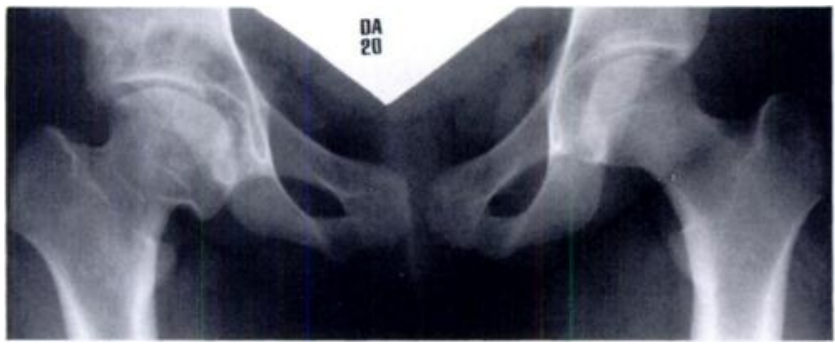

Fig. 4c

A patient without appreciable metaphyseal lucencies, and incomplete epiphyseal involvement. who later developed marked neck shortening. Figure 4a Early involvement, Catterall grade III, no metaphyseal changes. Figure $4 b$ - During remodelling there is significant metaphyseal abnormality. Figure $4 c$ Marked central growth abnormality is evident.

\section{RESULTS}

The average follow-up was 9 years 8 months (range 4 to 16 years). Thirty-five $(75 \%$ ) of the 46 patients had closure of the proximal femoral growth plate at final follow-up. Serial radiographs to determine the age and sequence of physeal closure were available for 35 hips in 33 patients. The mean age at closure of the proximal femoral epiphysis in these patients was 14 years 6 months (range 11 years 5 months to 16 years). The remaining 12 patients with 15 involved hips had open proximal femoral physes at final follow-up at a mean age of 12 years. Serial radiographs of both hips were available for all of these patients and the mean follow-up was six years.

Although asymmetrical growth did occur often in the proximal femoral physis, premature closure was extremely uncommon. Definite premature physeal closure was seen to have occurred in only three of the 35 patients who had skeletally mature proximal femora (Fig. 2).

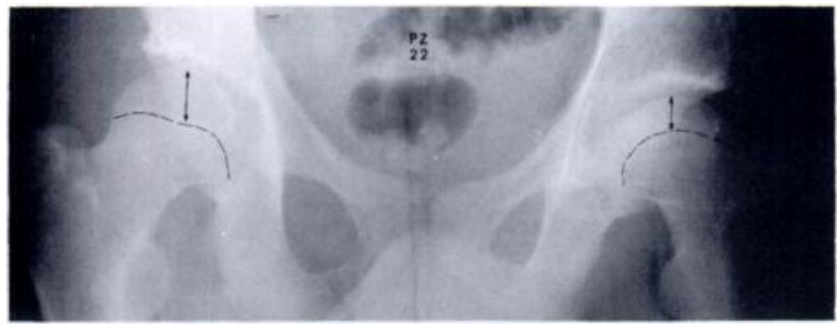

Fig. 5

Loss of epiphyseal height (12 against $22 \mathrm{~mm}$ ) accounts for most of the apparent shortening, the neck lengths being nearly equal.

Similarly, none of the 12 skeletally immature patients showed premature closure of any portion of the physis.

Physeal growth abnormalities were observed in 35 hips $(67 \%)$. In 26 of these the changes were symmetrical with a diminished neck length and proportionate decreases in the horizontal (MTH) and vertical (MTV) parameters, while nine hips showed asymmetrical growth abnormalities with a diminished neck length and a disproportionately greater decrease in the horizontal parameter (MTH).

Metaphyseal radiolucencies were seen in 40 hips $(77 \%)$. Two types were seen: those with sharp borders and those with ill-defined borders, and both types could be followed by either abnormal or normal growth. Of the 40 hips, growth abnormalities were seen in $28(70 \%)$ and no growth abnormalities in 12 (Figs 3 and 4). When only hips with metaphyseal radiolucencies of greater than $50 \%$ of the physeal width were analysed, the correlation was no better. Conversely, of the 12 without metaphyseal radiolucencies, five hips $(42 \%)$ had a growth abnormality and seven did not (Fig. 5). The association between metaphyseal cysts and growth abnormality was statistically significant at $p<0.05$, but the predictive value of cysts was low, as discussed later. The position of the metaphyseal radiolucency rarely correlated with the type of growth abnormality: neither of two hips with predominately medial radiolucencies had predominately medial diminution of growth. Many hips with a lateral cyst had a central growth abnormality, and many with a central cyst had a lateral growth abnormality.

Significant epiphyseal extrusion (greater than or equal to $20 \%$ ) was seen in only 19 hips, of which $12(63 \%)$ had a growth abnormality. However, 22 of the 33 hips with epiphyseal extrusion of less than $20 \%$ had a growth abnormality $(67 \%)$, and these two groups were not statistically different $(\mathrm{p}>0.05)$.

To assess the combined effects of epiphyseal extrusion and metaphyseal radiolucencies, hips with greater than $50 \%$ metaphyseal radiolucencies and $20 \%$ or more epiphyseal extrusion were studied as a separate group. Of the 14 hips with both features, eight $(57 \%)$ had a growth abnormality while six did not. This percentage is less than that for growth abnormality in the whole series.

No patient showed growth plate narrowing during 
the treatment stage of the disease, the mean and the median growth plate thickness being $2 \mathrm{~mm}$ (range 1 to $3 \mathrm{~mm}$ ). Widening of the femoral neck was common and was seen in 22 of the 40 patients with unilateral involvement.

Loss of epiphyseal height was seen in 28 of the 40 patients with unilateral hip involvement; this reached $10 \mathrm{~mm}$ in eight patients.

The mean neck-shaft angle at final follow-up in the 40 hips with unilateral involvement was $139^{\circ} \pm 14^{\circ}$ while in the contralateral normal hip it was $139^{\circ} \pm 17^{\circ}$. Moreover, the mean neck-shaft angle in hips with growth abnormality $\left(139^{\circ}\right)$ was not significantly different from the hips without growth abnormality $\left(139^{\circ}\right)$.

\section{DISCUSSION}

Although epiphyseal changes associated with Perthes' disease have been studied extensively, metaphyseal changes have been less well analysed. Catterall et al (1982), reporting the largest series of human specimens studied histologically, described four cases with an osteolytic metaphyseal lesion with sclerotic margins. These lesions contained fibrocartilage. Two other specimens had a radiographically widened growth plate; histologically these showed disorganised ossification with unossified cartilage streaming down into the metaphysis'. The growth plate itself was abnormal in all 11 specimens, with enlarged columns of unossified cartilage, but only one showed histological evidence of avascular necrosis in the metaphysis; this was focal in distribution. They conjecture that as a result of disruption of metaphyseal architecture there are differing rates of growth in the femoral neck. Significantly, they did not report that the physis overlying the metaphyseal 'cysts' was any more abnormal than in other areas. Growth arrest with premature closure secondary to focal physeal necrosis would therefore not be expected. Our radiographic findings agree with these conclusions: we observed definite premature growth plate closure in only three of 52 hips.

Our study supports the contention that growth abnormalities of the proximal femoral physis are a common sequel of severe Perthes' disease (Catterall grade III or IV); we frequently saw alterations in neck length, neck width and articulotrochanteric quotient. Similarly, we agree with Bowen et al (1984) that there are essentially two types of abnormal growth pattern symmetrical (central) and asymmetrical (lateral). Although metaphyseal radiolucencies were commonly seen, they did not serve as highly specific (only $60 \%$ of those with metaphyseal radiolucencies had a growth abnormality) or as highly sensitive ( $42 \%$ without metaphyseal radiolucencies had a growth abnormality) predictors of growth abnormality. Neither the size nor the site of the metaphyseal radiolucency predicted the occurrence or type of growth abnormality. Similarly, epiphyseal extrusion was not a specific or sensitive predictor and the combination of extensive metaphyseal radiolucencies and significant epiphyseal extrusion did not improve prediction. Many proximal femora showed a loss of height due to epiphyseal flattening, which on casual inspection may resemble neck shortening, but these phenomena represent two different types of growth deficiency.

Changes in the thickness of the proximal femoral growth plate have been associated with later growth abnormalities (Bowen et al 1984). We found this difficult to quantify, as the normal growth plate is only 2 to $3 \mathrm{~mm}$ thick. In many cases, the normal physis is irregular. We saw no cases of significant widening or narrowing before the disease was well into the remodelling stage. Further studies with larger numbers of patients and threedimensional analysis of the proximal femoral physis and its growth are needed to corroborate our findings.

Conclusions. Most physeal growth abnormalities in Perthes' disease do not seem to be due to early physeal closure by more than a year or two, and would not, therefore, be amenable to bar resection. The likelihood of growth abnormality remains difficult to predict. The presence of 'cysts' in the metaphysis does not have a high predictive value. Changes in the thickness of the growth plate are rare. The age and extent of epiphyseal involvement will require closer study. None of these factors should be used exclusively to dictate the type of surgery which is performed.

No benefits in any form have been received or will be received from a commercial party related directly or indirectly to the subject of this article.

\section{REFERENCES}

Barnes JM. Premature epiphyseal closure in Perthes disease. $J$ Bone Joint Surg [Br] 1980;62-B:432-7.

Bowen JR, Foster BK, Hartzell CR. Legg-Calvé-Perthes disease. Clin Orthop 1984;185:97-108.

Catterall A. The natural history of Perthes' disease. J Bone Joint Surg [Br] $1971 ; 53-\mathrm{B}: 37-53$.

Catterall A, Pringle J, Byers PD, et al. A review of the morphology of Perthes' disease. J Bone Joint Surg [ Br] 1982;64-B :269-75.

Stulberg SD, Cooperman DR, Wallensten R. The natural history of Legg-Calvé-Perthes disease. J Bone Joint Surg [Am] 1981;63A:1095-1108. 